\title{
Mastite com lesões sistêmicas por Staphylococus aureus subesp. aureus em coelhos
}

\author{
Mastitis with systemic lesions due to Staphylococus aureus \\ subesp. aureus in rabbits
}

\begin{abstract}
Sandra Davi Traverso ${ }^{1}$ Leonardo da Cunha ${ }^{2}$ Joaquim César Teixeira Fernandes ${ }^{3}$ Alexandre Paulino Loretti ${ }^{1}$ Adriana Rhoden ${ }^{4}$ Elsio Wunder Jr. $^{4}$ David Driemeier $^{1}$
\end{abstract}

\section{-NOTA-}

\section{RESUMO}

Em uma criação composta por 1800 coelhos, 33\% das matrizes apresentaram mastite e lesões cutâneas crostosas e purulentas. Estes animais apresentavam-se entre 10 a- 12 meses de idade e em segunda parição. Quinze coelhos afetados foram sacrificados e necropsiados. Na necropsia, além das lesões cutâneas haviam microabscessos em diversos órgãos. Das amostras coletadas isolou-se Staphylococcus aureus subesp. aureus. S. aureus subesp. aureus também foi isolado de "swab" nasal coletado do tratador encarregado de fazer o diagnóstico de gestação nas coelhas. Histologicamente, havia formação de múltiplos abscessos, presença de bactérias gram positivas em vasos sangüineos e linfáticos, além de êmbolos bacterianos nos tecidos. Nas mamas, observou-se tecido glandular normal associado a abscessos multifocais delimitados.

Palavras-chave: Staphylococcus aureus, mastites, lesões cutâneas, coelhos.

\section{ABSTRACT}

At a commercial rabbitry which was composed of 1800 New Zealand White rabbits, 30\% of the does had presented mastitis and purulent cutaneal lesions. The age of the animals ranged from 10 to 12 months and were at the second parturition. At necropsy, microabscesses were observed in several organs. Bacteriological samples collected from affected animals resulted Staphylococcus aureus subesp. aureus.. Additionally, the same agent has been isolated from a nasal swab collected from the person responsible for the pregnancy diagnosis. Histologically, there were multiple abscesses, gram positive bacteria within blood and lymphatic vessels, and bacterial emboli scattered in the tissues. In the mammas, normal glandular tissue associated with multifocal abscesses were observed.

Key words: Staphylococcus aureus, mastitis, cutaneal lesions, rabbits.

Staphylococcus aureus são bactérias gram positivas da família Microcaccaceae que causam processos supurativos, mastite e piodermite no homem e animais, sendo também encontradas na pele e mucosas de animais e pessoas saudáveis. Staphylococcus aureus é considerado a bactéria de maior patogenicidade em coelhos (CUBILLOS et al., 1986). A manifestação clínica mais característica desta enfermidade é a presença de dermatite exsudativa em coelhos lactantes e abscessos subcutâneos em coelhos de todas as idades (CAROLAN, 1986). Na maioria dos criatórios, os casos de infecção são esporádicos. Surtos de estafilococose em coelhos foram relatados nos EUA(HAGEN, 1963), Bélgica(OKERMAN et al., 1984), Inglaterra (HOLLIMAN \& GIRVAN, 1986) e Chile (CUBILLOS et al., 1986). A propagação indireta também pode ocorrer através do contato de pessoas que trabalham com os animais e por utensílios utilizados no manejo (CUBILLOS et al., 1986).

${ }^{1}$ Médico Veterinário, Setor de Patologia Veterinária, Faculdade de Veterinária (FV), Universidade Federal do Rio Grande do Sul (UFRGS), CP 15094, 91540-000, Porto Alegre, RS. E-mail: davetpat@vortex.ufrgs.br Autor para correspondência.

${ }^{2}$ Médico Veterinário, Secretaria da Saúde e Vigilância Sanitária de Porto Alegre, RS.

${ }^{3}$ Médico Veterinário, Professor substituto, Setor de Bacteriologia Veterinária, FV, UFRGS.

${ }^{4}$ Aluno do curso de Medicina Veterinária, FV, UFRGS. 
Feridas superficiais da pele constituem a principal via de entrada de Staphylococcus aureus. A pododermatite é freqüentemente encontrada em coelhos adultos mantidos em gaiolas, ou em coelhos de grande porte. Nas mastites, a bactéria atinge a glândula através de ferimentos produzidos pelos dentes dos filhotes ou decorrentes de traumatismos causados pelos arames das gaiolas. A glândula mamária é altamente suscetível à infecção estafilocócica durante a lactação (OKERMAN et al., 1984).

Staphylococcus aureus possui três tipos de exotoxinas: hemolisinas, enterotoxinas e leucocidinas e que determinam sua patogenicidade (MAYR 1993) O Staphylococcus aureus causa mastite gangrenosa devido à toxina que produz vasoconstrição isquemia necrose e gangrena (DEVRIESE et al., 1996). Cepas de S. aureus de 59 cultivos classificadas como de alta e baixa virulência indicaram que, pelo menos, duas marcas antigênicas determinadas por "western blot" com peso molecular de 27 e $29 \mathrm{kDa}$ eram comuns a todas as 27 culturas consideradas altamente patogênicas para coelhos (HERMANS et al., 2001) Adicionalmente, Staphylococcus aureus subesp. aureus (MacFADDIN, 2000) produz uma toxina que tem sido associada à vasoconstricção, trombose, isquemia e necrose, ocasionando, às vezes, mastite gangrenosa. A formação de uma coagulase do plasma livre ou ligada às células, além da produção de uma nuclease termoestável, é o principal critério para diferenciar estafilococos coagulase positivos de estafilococos coagulase negativos. (MAYR, 1993). Há uma alta correlação entre as cepas de Staphylococcus sp. que produzem coagulase e as produtoras de toxina (OKERMAN et al., 1984). Há no entanto, patogenicidade comprovada em espécies de estafilococos coagulase negativa como $\boldsymbol{S}$. epidermidis que foi encontrado em lesões cutâneas, endocardites e mastites em animais ( MAYR, 1993).

A infecção por Staphylococcus aureus pode ocorrer de forma aguda, subaguda ou crônica. Os animais infectados somente apresentam manifestações clínicas quando apresentam baixa imunidade. Há predominantemente uma manifestação cutânea e posteriormente uma generalização da infecção. (OKERMAN et al., 1984). Os sinais clínicos dependem do modo e duração da infecção. Nas formas aguda e subaguda, há tumefação e avermelhamento da pele e tecido subcutâneo e, às vezes, da glândula mamária. $\mathrm{Na}$ forma crônica da infecção, são observados abscessos na mama e tecido subcutâneo, associados ou não a pododermatites ulcerativas e hemorrágicas com formação de crostas e exsudato purulento, que podem ser observadas em todos os membros. A septicemia pode resultar em morte hiperaguda com sinais clínicos pouco específicos. Animais que sobrevivem podem desenvolver abscessos nos órgãos internos, como coração, rim, pulmão, fígado, e baço. Osteíte e osteomielite, similares às observadas em actinomicose, têm sido descritas. A mortalidade em recém-nascidos e coelhos jovens pode ser alta em conseqüência da mastite das fêmeas lactantes (CUBILLOS et al., 1986; DEVRIESE et al., 1996).

O presente relato descreve a ocorrência de mastite por Staphylococcus aureus subesp. aureus com lesões disseminadas em coelhas de um criatório da raça Nova Zelândia Branco, onde havia um total de 1800 animais. Das 180 matrizes desta criação, 60 (33\%) apresentaram mastite. Estas matrizes eram animais de segunda parição e estavam entre 10 e 12 meses de idade. Em alguns casos, a mastite envolvia uma única glândula, e, em outros, várias glândulas mamárias estavam afetadas. Notava-se um aumento de volume com consistência firme levemente nodulada. Os animais emagreciam progressivamente.

Quinze coelhas afetadas foram necropsiadas e amostras de diversos tecidos incluindo as glândulas mamárias foram coletadas e processadas para exames histopatológicos. À necropsia, observouse que a principal lesão estava presente nas mamas e consistia de abscessos contendo pus (Figura 1) de cor clara e consistência cremosa, além de pequenas nodulações irregulares. Vários destes animais apresentavam abscessos em outros órgãos incluindo coração, pulmão, fígado (Figura 2) e rins. Também eram observados abscessos de aproximadamente $0,5 \mathrm{~cm}$ de

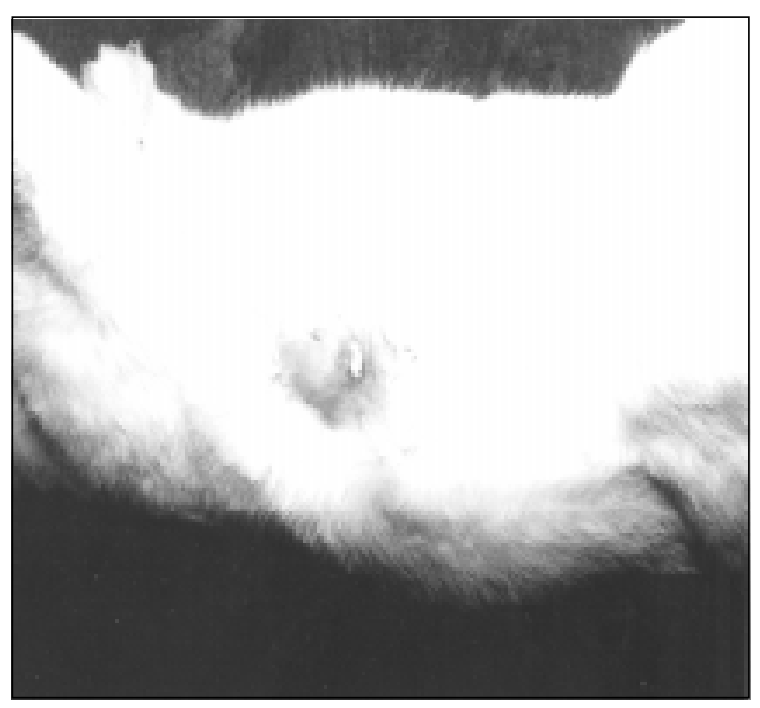

Figura 1 - Coelha, apresentando abscesso na região mamáriaa direita.

Ciência Rural, v. 33, n. 2, 2003. 


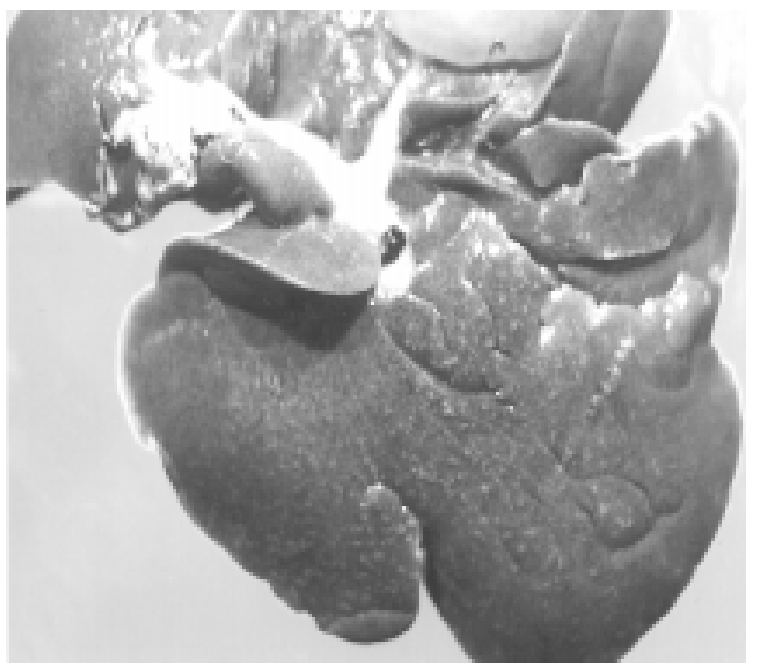

Figura 2 - Fígado - coelha, com presença de diversos microabscessos disseminados pelo parênquima. Coloração HE

diâmetro na musculatura do tronco e membros, além de pododermatite, em alguns casos.

Vinte e duas amostras de tecidos que incluíam mama, fígado, rim e pulmão provenientes de coelhas com mastite foram cultivadas em ágar Mueller Hinton contendo $10 \%$ de sangue citratado de ovino e no meio de Chapman-Stone ${ }^{1}$ e incubados a $37^{\circ} \mathrm{C}$ por 24 horas. O tamanho e a hemólise das colônias foram feitas nas placas de ágar sangue e a produção de pigmento avaliada nas placas de chapman-stone. A atividade da coagulase e do fator "clumping" foram determinados em tubos e em lâminas pelos testes convencionais com plasma citratado de coelho. As provas bioquímicas foram feitas de acordo com os métodos preconizados por MacFADDIN (2000).

Das 22 amostras cultivadas em 18 foram isoladas Staphyloccocus aureus subespécie aureus e 4 amostras foram negativas. Dos "swabs" nasais de três tratadores, em dois deles, foram isolados Staphylococcus epidermidis e do terceiro tratador, responsável pelo diagnóstico de gestação, foi isolado Staphyloccus aureus subespécie aureus. Fragmentos de tecidos fixados em formol e processados por métodos convencionais revelaram múltiplos abscessos (Figura 3) e êmbolos bacterianos em diversos tecidos.

No presente surto de estafilococose registraram-se severas perdas econômicas, confirmando relatos anteriores (HAGEN, 1963; OKERMAN et al., 1984). A via de transmissão entre animais do agente Staphylococcus aureus pode ser direta por via aerógena e muitos coelhos podem ser portadores do agente sem sinais clínicos. A via indireta inclui uten-

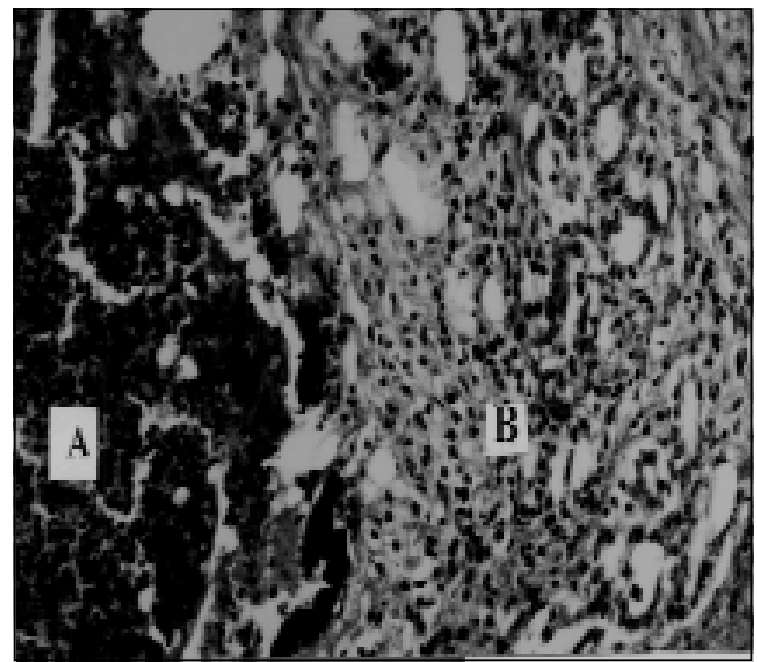

Figura 3 - Glândula mamária - coelha, demonstração da presença de um abscesso (A) associado a tecido glandular normal (B.).Obj $20 \mathrm{HE}$

sílios e, inclusive, os tratadores dos animais são citados como importante fonte de contaminação (CUBILLOS et al., 1986). Há possibilidade, embora não comprovada, de ter ocorrido, no presente relato, a transmissão de Staphylococcus aureus subesp. aureus entre humanos e coelhos.

A disseminação do agente formando êmbolos sépticos em diversos tecidos, principalmente quando retidos em vasos de menor calibre, exemplifica uma tromboembolia bacteriana semelhante àquela observada por Actinobacillus equuli em potros (MAYR, 1993).

\section{AGRADECIMENTOS}

Os autores agradecem ao CNPq - Pronex por auxílios prestados ao Laboratório de Patologia Veterinária - Faculdade de Veterinária, UFRGS.

\section{FONTES DE AQUISIÇÃO}

${ }^{5}$ Difco Laboratories PO Box 331058 Detroit MI 48232-7058 USA

\section{REFERÊNCIAS BIBLIOGRÁFICAS}

CAROLAN, M.G. Staphylococcosis in rabbits. Vet Rec, v.119, p.412, 1986.

CUBILlos, V.; PAREDES, E.; FIELDER, H.H. Staphylococcosis in rabbits. Arch Med Vet, v.18, p.14, 1986.

DEVRIESE, L.A. et al. A new pathogenic Staphylococcus aureus type in comercial rabbits. J Vet Med, v.43, p.313-315, 1996.

Ciência Rural, v. 33, n. 2, 2003. 
HAGEN, K.W. Disseminated staphylococcic infection in young domestic rabbits. J Am Vet Med Assoc, v.142, p.1421-1422, 1963.

HERMANS, K. et al. Secreted antigens as virulence-associated markers in Staphylococcus aureus strains from rabbits. Vet Microbiol, v.81, p.345-352, 2001.

HOLLIMAN, A.; GIRVAN, G.A. Staphylococcosis in comercial rabbitry. Vet Rec, v.119, p.187, 1986.
MacFADDIN, J.F. Biochemical tests for identification of medical bacteria. Baltimore : Lippincot Williams \& Wilkins, 2000. 912p.

MAYR A. Rolle/Mayr Medizinische Mikrobiologie, Infektions- und Seuchenlehre. Lehrbuch für Praxis und

Lehre. 6 ed. Stuttgart : Ferdinand Enke Verlag, 1993 887p.

OKERMAN,L. et al. Cutaneous Staphylococcosis in rabbits. Vet Rec, v.114, p.313-315, 1984. 